\section{Plutonium-244 on the Eurth}

ONE of the most fascinating detective stories in the history of cosmological and cosmogonical science seems to be solved with the publication in this issue of Nature (page 132) of the discovery of plutonium-244 in nature. A joint team of scientists from the Los Alamos Scientific Laboratory and the General Electric Company discovered the elusive nucleus in an old Precambrian rare-earth mineral called bastnasite. Everybody had suspected the natural existence of ${ }^{244} \mathrm{Pu}$ by the clues it had left from the early days of the solar system, and now it has actually been found.

The clues in this mystery began accumulating in 1960 when Kuroda suggested that the excess xenon gas isotopes ${ }^{131} \mathrm{Xe},{ }^{132} \mathrm{Xe},{ }^{134} \mathrm{Xe}$, and ${ }^{136} \mathrm{Xe}$, which he had found in the achondritic meteorite Pasamonte, had resulted from the spontaneous fission of some heavy radioactive nucleus that had a sufficiently long half-life to have been incorporated into the meteorites when the solar system formed and to have remained there until the meteorites cooled and solidified, enabling them to trap the noble-gas fission fragments. Kuroda specifically suggested ${ }^{244} \mathrm{Pu}$, which has a half-life of $82 \times 10^{6}$ years. Other workers were also able to find a reproducible spectrum of fission-like xenon in other achondrites, where the low concentration of xenon arising from other sources (primaeval xenon) and the high concentrations of uranium, which chemically accompanies $\mathrm{Pu}$, presented favourable circumstances for the detection of this xenon component.

Then two years ago an exceptionally high concentration of this same isotopic pattern of xenon isotopes was found in the uranium-rich mineral whitlockite, from the St Severin chondritic meteorite. The exciting new clue in this case was that this same whitlockite mineral showed, upon etching, an excess of fission tracks; however, it still could not be argued that the fissioning culprit was ${ }^{244} \mathrm{Pu}$.

A nagging problem throughout these investigations had been that the yields of xenon isotopes in ${ }^{24} \mathrm{Pu}$ fission had never been experimentally determined because of the difficulty in assembling a large enough sample of ${ }^{244} \mathrm{Pu}$. Thus the mysterious isotope ratio observed reproducibly in meteorites, ${ }^{131} \mathrm{Xe}:{ }^{132} \mathrm{Xe}:{ }^{134} \mathrm{Xe}:{ }^{136} \mathrm{Xe}=25: 88: 92: 100$, could not with certainty be attributed to ${ }^{244} \mathrm{Pu}$. Recognizing the importance of these ratios, a team from the Oak Ridge National Laboratory electromagnetically separated $13 \mathrm{mg}$ of ${ }^{244} \mathrm{Pu}$ from large quantities of neutronirradiated plutonium. After a 23-month wait to allow sufficient ${ }^{244} \mathrm{Pu}$ fission, a Berkeley team confirmed these fission isotopic ratios directly (Science, 172, 837; 1971). This was the final clue that proved that ${ }^{244} \mathrm{Pu}$ existed in the solar system when the meteorites formed. It only remained to detect its small residues in some object today.

The difficulty in finding natural ${ }^{244} \mathrm{Pu}$ is that the solar system formed about 60 half-lives ago, so that the average concentration of ${ }^{244} \mathrm{Pu}$ should be only about $\left(\frac{1}{2}\right)^{60}$ of its concentration when the meteorites formed! Inasmuch as an upper limit to that absolute concentration would be expected to be only $3 \times 10^{-25} \mathrm{~g}$ per gram of earth even if ${ }^{244} \mathrm{Pu}$ were originally as abundant as ${ }^{232} \mathrm{Th}$, surely an overestimate by a factor near 100 , it was clear that the search must be made in some mineral that would have, in the long and complicated chemical history of the Earth, concentrated the plutonium.

Because the chemistry of $\mathrm{Pu}$ is similar to the rare earth Ce, the Los Alamos group studied a large inventory of the extractant used by the Molybdenum Corporation of America to purify $\mathrm{Ce}$ from old bastnasite ores. The $\mathrm{Ce}$ is almost $10^{6}$ times more concentrated in this mineral than its average concentration; and, sure enough, the long sought ${ }^{244} \mathrm{Pu}$ was there too. Although the chemical enrichment of $\mathrm{Pu}$ would have to be about $10^{8}$ (that is, about 100 times more concentrated than $\mathrm{Ce}$ ) above the ${ }^{244} \mathrm{Pu}$ abundance of $7 \times 10^{-27} \mathrm{~g} / \mathrm{g}$ expected from the meteoritic concentrations of fission xenon, the results seem convincing. With this discovery, ${ }^{24} \mathrm{Pu}$ leaves the category of "extinct radioactivities" and joins ${ }^{235} \mathrm{U}$ in the category of "almost extinct radioactivities".

The cosmological significance of these discoveries is both simple and profound. When the primaeval meteoritic abundance of ${ }^{244} \mathrm{Pu}$ is considered in conjunction with that of ${ }^{129} \mathrm{I}$, an extinct radioactive species that decays to ${ }^{129} \mathrm{Xe}$ leaving a different xenon anomaly in the meteorites, it can be concluded that about $1.8 \times 10^{8}$ years elapsed from the time when a portion of interstellar gas collapsed into the gas cloud that was to form the solar system and the time when the newly formed meteorites were cool enough to retain noble xenon gas. This well determined interval for the formation and cooling of the meteorites poses a firm challenge to theories of the formation of solid objects. But the implications do not stop there. Because ${ }^{244} \mathrm{Pu},{ }^{238} \mathrm{U},{ }^{235} \mathrm{U}$, and ${ }^{232} \mathrm{Th}$ are all synthesized in comparable amounts in exploding objects, their relative abundances reveal that nucleosynthesis began in the galaxy about $12 \pm 2 \times 10^{9}$ years ago and occurred continuously from that time until the time the solar system formed about $4.7 \times 10^{9}$ years ago. This age pattern for galaxies must now be regarded as a prime fact for cosmology.

There is, however, another possible interpretation of the Los Alamos discovery. The Los Alamos group acknowledge that heavy cosmic rays may bombard the Earth with a flux such that the average terrestrial concentration of ${ }^{244} \mathrm{Pu}$ would be about $5 \times 10^{-25} \mathrm{~g} / \mathrm{g}$. But because the Precambrian bastnasite is, as a mineral deposit, older than $5 \times 10^{8}$ years, the ${ }^{244} \mathrm{Pu}$ concentration would now be only about $5 \times 10^{-27} \mathrm{~g} / \mathrm{g}$ if it had been deposited on the Precambrian Earth by cosmic rays. They suggest that the detection of natural ${ }^{244} \mathrm{Pu}$ in younger minerals can illuminate this possibility. Thus an intriguing cloud of uncertainty still surrounds their remarkable discovery. 